\title{
Artificial Intelligence and Space Technologies: Legal, Ethical and Technological Issues
}

\author{
Larysa Soroka
}

Ph.D. in Law, Associate Professor, Scientific Institute of Public Law (Kyiv, Ukraine)

E-mail: lsoroka_kw@ukr.net

https://orcid.org/0000-0002-6979-6049

\section{Kseniia Kurkova}

Ph.D. in Law, Scientific Institute of Public Law (Kyiv, Ukraine)

E-mail: kurkova ksenya@ukr.net

https://orcid.org/0000-0002-4259-5511

\begin{abstract}
The article is devoted to the study of the specifics of the legal regulation of the use and development of artificial intelligence for the space area and the related issues of observation of fundamental human rights. Some approaches to the definition of artificial intelligence and the peculiarities of legislative provision of the corresponding area are considered. The authors concluded that, in order to regulate the use of artificial intelligence and space technologies, an international treaty should be adopted under the auspices of the United Nations, which would cover the creation of a law enforcement international agency monitoring artificial intelligence the observation of basic human rights in the specified area.

Keywords: artificial intelligence, space, human rights, legal norms, ethical norms.
\end{abstract}

Received: December 21, 2018; accepted: February 27, 2019

Advanced Space Law, Volume 3, 2019: 131-139.

https://doi.org/10.29202/asl/2019/3/11

\section{Introduction}

The ambitious short-term and long-term goals set by various national space agencies require a radical advance of new technologies into the space sector, one of which is undoubtedly the development of intelligent space agents. In recent years, this has led to an increasing interest in the artificial intelligence of the entire aerospace community. Indeed, technologies and machines that can independently perform various functions in the areas such as space, where conditions are hostile and dangerous to human life, are increasingly used. Therefore, one of the complicated legal problems of our time is the increasing use of and dependence on technology and processes related to artificial intelligence and space technologies.

(C) Soroka, Larysa, 2019

(C) Kurkova, Kseniia, 2019 
Artificial intelligence was designed to facilitate the processing of large volumes of data, both through self-study and the ability to adapt to changing circumstances. Such properties of artificial intelligence provides for the humanity facing various ethical, political and legal questions arising from its use for scientific, commercial and potentially strategic goals both on Earth and in outer space.

Technologies of artificial intelligence are developing intensively today, both due to the development of technologies of stable neural networks and cloud computing infrastructure, technologies of fuzzy systems, entropy control, swarm intelligence, evolutionary calculations, and many others. Throughout the world, representatives of industry, governments, academics and civil society are discussing how to set the necessary regulatory framework using ethical or technical approaches.

\section{What is artificial intelligence?}

The inventors have long dreamed of creating a thinking machine. These dreams go back to Ancient Greece. The characters of the myths - Pygmalion, Dedal, Hephaestus - could be called legendary inventors, and their creations - Galatea, Talos and Pandora - artificial life. When thinking about programmable computers for the first time a hundred or more years before building a computer, humans wondered if they could be intelligent. Today, artificial intelligence is a rapidly developing discipline with numerous applications. We want to have intelligent programs that could automate routine work, understand speech and images, make medical diagnoses and support research [Goodfellow et al., 2018: 21].

Artificial intelligence is intelligence demonstrated by machines, programs and computers that can independently think, learn and make decisions. This form of intelligence is already integrated into our everyday life: from musical services that recommend new music based on our interests to new cars with automatic control.

A type of artificial intelligence is a dueling one, which is a training program in which two machines will train each other, and both will learn from their mistakes.

The first person to speak of this was one of the most famous scientists in the field of artificial intelligence - Ian Goodfellow. It should be noted that the 34-year-old scientist made a name for himself in 2014 as the author of the concept of GAN - generative adversarial neural networks. In this system, two neural networks contest with each other: the one that directly creates the content ("generator"), and the one, which analyzes it ("discriminator"), comparing the work done with content standards [Irtlach, 2019].

Geospatial intelligence is one of many ways to use artificial intelligence for national defense in outer space. Geospatial intelligence extracts and analyzes images, geospatial information about objects and events on Earth and near it [Walker, 2018]. An important part of geospatial intelligence is the analysis of images - the process of studying the image obtained from satellites or aircraft, to identify features, describe activities and interpret what is happening in this place on the surface of Earth.

Taking into account the proliferation of data collection that occurs in technological devices, some of the following important things in the geospatial intellect are tiny black boxes on board the satellites that can handle huge volumes of data in space and offer their instant analysis. Processing and analysis of geospatial data in real time is considered to a "Holy Grail" in military intelligence [Sim, 2018]. 
The issues of AI management and control are important for developers and for civil society as well. Generally, intelligent control is an automatic control in which program algorithms are not predefined in advance, but formed by the control system itself, based on formalized descriptions of purposes, knowledge of possible actions, and information on current changes in the state of the environment [Girimonte \& Izzo, 2007].

Artificial intelligence can very quickly analyze a huge amount of data and offer short judgments that can be used to make decisions. Nevertheless, the main problem in this context is the degree to which the analysis of artificial intelligence can be used to develop objective judgments that not only reproduce and legitimize existing discrimination or inequality.

\section{Artificial intelligence and outer space}

During the last 60 years in the society there has appeared a transition from absolute euphoria in designing, perception of space activities and forecasting its results to awareness of the problems and restrictions, to economic pragmatics and growing criticism of the space activity area that, despite all its outstanding achievements, significant results and huge development potential, increasingly lacks effectiveness compared to other branches of human activities in the 21st century [Krichevsky, 2018: 93].

Modern space communication systems make use of sophisticated software to support scientific and space missions. Thanks to the use of artificial intelligence and machine learning, satellites can seamlessly manage these systems, making decisions in real time without waiting for instructions. Based on artificial intelligence, cognitive technologies are designed to make communication networks more effective and sustainable for the missions exploring the depths of outer space.

A cognitive radio can mitigate the problems arising in the outer space environment, such as electromagnetic radiation emitted by the sun and other celestial bodies that fills the space with noise and can interrupt certain communication frequencies. Cognitive radio applications can transmit beyond the range of interference or eliminate distortions within the range using machine learning.

For example, when a Mars rover conducting exploration of Mars needs to contact Earth, it takes up to 24 minutes to pass the signal between the two planets in one direction. It is rather long time for making decisions, that is why engineers are increasingly providing space robots with the ability to make decisions by themselves [Downer, 2018].

For a long time, space robots could control some on-board systems, such as power consumption. Now, artificial intelligence provides rovers and orbital apparatuses with the ability to collect and analyze scientific data and decide what information to send back to Earth that can be done without any human involvement.

Since May 2016, NASA has tested an autonomous system on the Curiosity rover, which was sent to explore the Gail crater on Mars. A system called AEGIS (Autonomous Exploration for Gathering Increased Science) is reported to work well and have the potential for accelerating scientific discoveries. AEGIS was originally designed for the Opportunity rover on Mars in 2010 to help it identify and take pictures of boulders. However, since then it has been improved to examine them more closely and distinguish between certain materials. Artificial intelligence will play an important role in solving the mysteries of the Red Planet and, possibly, other planets in the future [Sim, 2018]. 
In the future, it is likely that AI will also resolve the issues that will arise in outer space, rather than waiting for human prompts from Earth. For example, we will send space ships farther into outer space than ever before. Because of this distance, they are not always within the reach of transmitting information back to Earth. This means that a spacecraft must be smart enough to learn and ultimately decide when and how to return the data they have collected. As we travel further into the unknown, these spacecrafts will also have to make their own decisions in new conditions (for example, new gravitational forces, different temperature ranges and unknown collisions with dust or an asteroid).

When sending astronauts to longer missions and other destinations in the Solar System, artificial intelligence will also be used to help people react to unexpected events. The software that can respond and make decisions in emergencies will better prepare astronauts for these future missions. For example, if a medical procedure is to be conducted on board a spacecraft, an astronaut that is far from Earth will not always be able to get a live conversation with a physician or surgeon on Earth. Instead, the spacecraft will be able to learn and reason to help in such a situation.

In June 2018, a small robot named CIMON flew in the SpaceX Dragon cargo capsule to the space station. Designed by European Airbus on behalf of the German DLR, the 5-kilogram sphere can communicate with people whom it can recognize using face recognition software [Skripin, 2018]. By conducting experiments and helping astronauts, the robot was a valuable mission partner during its short two-day stay at the station. This project is intended to demonstrate how people and machines can effectively interact and collaborate in space missions.

In general, new spacecraft will be able to be more independent, self-dependent and autonomous. Since scientists cannot predict when or where space discoveries will be made, artificial intelligence will be a useful tool for helping space technology to keep track of things, notice important discoveries and send important information to us on Earth. Finally, artificial intelligence will diminish costs by reducing the necessary earthly human activities that also means it can reduce the risks for human workers.

\section{Legal bases and possible risks of using artificial intelligence and space technologies}

As previously mentioned, we live in the most technologically progressive period of our existence. Because of this, humans now have a better understanding of human civilization, which includes space exploration, safer transport and, in general, better quality of life.

What makes this more exciting, it is a wide range of opportunities with artificial intelligence and space technologies. However, we still have to understand what the final results of their use will be. Not to mention that even scholars cannot agree on a precedent that will arise from the use of artificial intelligence. Stephen Hawking once said in 2017 that artificial intelligence can lead to the end of the civilization we know. Other researchers and scientists, although having less gloomy predictions, are still concerned about the current situation with the use of artificial intelligence and its implications, but it only shows how difficult it is to set the rules and regulate the specified field [James \& Roper, 2018].

In "Liability for Damages Caused by Artificial Intelligence" noted that technologies of artificial intelligence differ in spontaneity, constant development and transformations. For this reason, the legal and regulatory framework regulating this area should be: firstly, universal, in 
order to be effective, regardless of changes in information technology, or, secondly, constantly adjustable to ensure its effectiveness under conditions of intense changes in information technologies. At the same time, constant adjustments to the legislation as a reaction to the changes in the field of information technologies may turn out to be difficult to implement due to relatively static and pronounced consistent nature of the activities of state authorities [Čerka et al., 2015]

Back in the 1980s, international law scholars began to explore whether the development of artificial intelligent machines, such as robots, require any adaptation or extension of existing legal and regulatory frameworks, e.g. concerning liability or legal status. Most of this work was related to agent technologies in software systems. Since robotics was still a science fiction but not a fact, many of these studies were fragmentary in their nature. They addressed important legal issues that should be covered by (future) robotics law, but did not contain any specific measures or rules and did not apply to existing legal systems.

In connection with the intensification of commercial and mining activities in the Arctic, on the high seas, and soon in the outer space, the rules of international law on liability of states for the activities carried out in these areas deserve further attention and research. These legal norms also demand the establishment of such general rules on the use of artificial intelligence, which neither at present nor in the future would violate the fundamental human rights.

The problem of regulating new technologies in Europe has been solved by almost every national legal system. Therefore, the developments in this area include a large number of studies on the relationship between law and science, as well as between law and technology.

In March 2012, the European project RoboLaw was launched, which focused on the issues facing the definition of the legal "status" of robotics, nanotechnology, neuroprostheses, and computer-brain interfaces, i.e. in the areas where little has been done so far [Robolaw, 2012].

The radical novelty of these technological applications and tools calls for an original and more complex study, characterized by an interdisciplinary method and a comparative analysis of various approaches adopted in various legal systems. Several research institutes around the world explored aspects of the regulatory implications of the developments in the field of robotics. Nevertheless, the settlement of this area (both in Europe and beyond its borders) is still fragmented.

Matthew Scherer reached a similar conclusion, believing that, until recently, the development of artificial intelligence took place in a kind of normative vacuum (although not absolute); with the exception of rules concerning unmanned vehicles and aircrafts in some states. Until present, there have been adopted very few provisions that directly address unique and specific problems raised by artificial intelligence. There is practically no judicial practice in this area [Scherer, 2016: 356].

What are the current legal acts regulating the use of artificial intelligence in general and in the space area in particular? We believe that the biggest problem facing the law and artificial intelligence can be broadly referred to as "regulation". More precisely, will governments regulate artificial intelligence, and if so, how? This all-embracing question permeates the entire area and deals with different specific issues.

Today, there are two ways to resolve the use of artificial intelligence. The first method assumes that you need to solve problems as they come. If there is no problem, there is no need to regulate it. In other words, a non-interactive approach should be applied. The reason, he said, was that "early (normative) intervention can prevent or even block certain paths to innovation". 
The second method is proactive, i.e. universal pre-emptive norms are mandatory for all, without waiting for problems to appear that need to be solved. We agree with the followers of this method and support the adoption of the International Treaty on the Regulation of Research and Development in the field of artificial intelligence. In the Treaty, it is also necessary to provide for international supervision of the implementation of the rules and establish an international law enforcement agency which will carry out such supervision.

For civil society, the issues of artificial intelligence regulation are also relevant. For many years, "free" services such as search engines, e-mail and social networks have been distributed. But the fact that these services are "free" is misleading. Consumers use such services without a monetary payment, but they pay in other ways — as a rule, they are exposed to advertising and allow to collect their personal data. The collected data, in their turn, are of tremendous value to service providers.

In 2018, public awareness of the confidentiality of data has increased. From a scandal with Cambridge Analytica to countless security breaches that reveal user data, people have learned that misuse of data can cause serious problems [Facebook, 2019].

Taking into account the mentioned problems and the growth of civil activity on this issue, the General Data Protection Regulation (GDPR) of the European Union [EU General, 2016] was adopted. After four years of preparation and debate, the GDPR was finally approved by the EU Parliament on April 14, 2016, and came into force on May 25, 2018. Organizations that do not comply with the requirements specified in the rules may be imposed considerable fines.

What changes occurred after the adoption of GDPR? First of all, this is an extraterritorial application. The rules apply to all companies processing personal data of data subjects residing in the EU, regardless of the location of the company. Previously, the territorial applicability of the directive was ambiguous and related to the processing of data "in the context of the institution's territory". Following a series of high-profile lawsuits, it was decided that GDPR refers to the processing of personal data by controllers and processors in the EU, regardless of whether the processing takes place in the EU or not. GDPR also applies to the processing of personal data of data subjects in the EU by a controller or processor not established in the EU, where the activity is related to: offering goods or services to EU citizens (regardless of whether payment is required) and monitoring behavior taking place in the EU. Non-EU enterprises processing EU citizens' data also have to appoint a representative in the EU [EU General, 2016].

California has adopted a similar measure - the California Consumer Protection Act of 2018 [AB-375, 2018], which will come into force in 2020. The law regulates the way companies can collect and sell personal data and provide individuals with substantial rights addressing their data.

In addition to the above laws, on May 16, 2018, the Toronto Declaration: Protecting the rights to equality and non-discrimination in machine learning systems was signed [Toronto Declaration, 2018], and on December 4, 2018 - the Montreal Declaration [Montreal Declaration, 2018].

The Montreal Declaration was the result of long deliberations among experts, lawyers and politicians, stakeholders in the industry, civil society organizations and citizens. The Declaration defines the basic ethical values and principles that support the fundamental human rights as the basis for future policy and regulatory development of technology and applications for artificial intelligence. 


\section{Human rights}

Artificial intelligence is a major form of scientific and technological progress that can generate considerable social benefits. The development of AI, however, poses ethical challenges and social risks. It is incumbent on the various public and private stakeholders and policymakers, at the local, national and international levels, to ensure that the development and deployment of AI are compatible with the protection and fulfilment of fundamental human capacities and goals [Montreal Declaration, 2018].

The use of artificial intelligence and space technologies by law enforcement agencies is also an acute issue today. On the one hand, artificial intelligence and space technologies can help reveal or prevent a crime in the ways that were previously impossible. On the other hand, they should not be used for inappropriate discrimination or unjustified intrusions into one's personal life.

For example, automatic vehicle license plate readers take pictures of such signs, fix the date, time and GPS coordinates of a car and upload them to a database to which law enforcement authorities can access. "Predictive Policing" uses criminal and social databases to predict the likelihood of a crime and the likelihood of committing a violent crime [Richardson et al., 2019].

The use of artificial intelligence by police and in supervisory activities, as well as the observation of interests in legal and ethical disputes over the expediency of such use, is not an easy task. It is hoped that officials and technology companies are aware of the need to balance competing interests so that artificial intelligence and space technologies can help law enforcement authorities and the military without any prejudice to private rights.

The legal framework has already been approved around the world and can help mitigate the impact of new technologies on human rights, while using only ethical rules is inappropriate. As already noted, giving individual companies the right to independently develop self-regulation rules means transferring too much authority to such companies and will inevitably lead to fragmentation of approaches. The burden of settling these problems lies with companies and governments as well as civil society. By working together, they will be able to identify effective and fair policies in the field of artificial intelligence and human rights.

\section{The United Nations role}

Those who work on artificial intelligence for commercial purposes may wonder why they should take care of human rights. Stakeholders increasingly confer responsibility for enforcing rights on a private-sector [Droubi, 2016]. Therefore, technology companies hurry to develop and implement ethical standards in good faith: Microsoft announced that it adopted the Artificial Intelligence Principles to manage internal research and developments, Salesforce hired a "chief ethics officer for the use of artificial intelligence", and Google created an advisory board on ethics [van Veen \& Cath, 2018].

However, many of these strategies do not mention human rights at all, including the absence of any reference to the United Nations Guidelines on Business and Human Rights, commonly known as the "GDPR Principles", which outline the responsibilities of corporations in the field of human rights. Therefore, the fundamental problem of ethical approaches lies in their dependence on corporate self-control. Instead, we offer to switch to external supervision.

Unlike ethics, law and external supervision are supported by the force of states. Taken together, this means that we need new laws to impose harsh constraints on how artificial intelligence is used to enforce human rights. The task of the ethics councils, as well as the 
chief ethics officers, internal principles, etc. is to raise awareness, stimulate self-criticism and serve "conscience" for the technology industry.

At present, establishing common rules and implementing external international surveillance can be provided by only one structure - the UN. As mentioned above, in 2011, the UN adopted a milestone document — Guiding Principles on Business and Human Rights calling for industry to respect and protect human rights [Guiding, 2011]. These principles establish common rules for technology companies that they should rely upon when creating artificial intelligence products to ensure that these developments do not violate fundamental human rights.

\section{Conclusions}

The UN guidelines, although being an important milestone in the area of business and human rights, are only a starting point for the observation of human rights in the technical sector.

We believe that those who work directly on the development of artificial intelligence need to be regulated on the basis of "rigid" laws along with technical standards, so that human rights are not violated. At the same time, those working in the field of human rights should actively participate in managing and monitoring the use of artificial intelligence. When necessary, they should be willing to refer to the human rights framework to challenge how artificial intelligence is being developed and used by business or government. Civil society and artificial intelligence developers should work together to help assess risk areas and anticipate the needs of vulnerable groups. Only if the parties concerned work together in the field of human rights protection, it is possible to avoid or minimize violations in the area of the use of artificial intelligence and space technologies.

\section{미] References}

AB-375 Privacy: personal information: businesses. Assembly Bill No. 375 CHAPTER 55 An act to add Title 1.81.5 (commencing with Section 1798.100) to Part 4 of Division 3 of the Civil Code, relating to privacy. [Approved by Governor June 28, 2018. Filed with Secretary of State June 28, 2018] https://leginfo.legislature.ca.gov/faces/billTextClient. xhtml?bill_id=201720180AB375

Čerka, Paulius, Jurgita Grigienè, and Gintarè Sirbikytè. Liability for Damages Caused by Artificial Intelligence. Computer Law \& Security Review. 31 (3), 2015. http://dx.doi. org/10.1016/j.clsr.2015.03.008

Downer, Bethany. The Role of Artificial Intelligence in Space Exploration, 2018. https://www. reachingspacescience.com/single-post/AI-in-SpaceExploration

Droubi, Sufyan. Transnational Corporations and International Human Rights Law. Notre Dame Journal of International and Comparative Law vol. 6, issue 12016 . https://scholarship. law.nd.edu/cgi/viewcontent.cgi?article $=1048 \&$ context $=$ ndjicl

EU General Data Protection Regulation, "Regulation (EU) 2016/679 of the European Parliament and of the Council of 27 April 2016 on the Protection of Natural Persons with Regard to the Processing of Personal Data and on the Free Movement of such Data, and Repealing Directive 95/46/EC (General Data Protection Regulation)". Official Journal of the European Union, 119 (1), 2016. http://eur-lex.europa.eu/legalcontent/EN/TXT/HTML/?uri=CELEX:32016R0679\&from=EN. 
Facebook to be fined \$5bn over Cambridge Analytica scandal. BBC News. 2019 https://www. bbc.com/news/world-us-canada-48972327

Girimonte, Daniela, and Dario Izzo. Artificial Intelligence for Space Applications. In: Schuster A.J. (eds) Intelligent Computing Everywhere. Springer, 2007. https://doi. org/10.1007/978-1-84628-943-9_12

Goodfellow, Ian, Bengio Yoshua, and Aaron Courville. Deep Learning. MIT Press, 2018.

Guiding Principles on Business and Human Rights, United Nations, June 16, 2011, https:// www.ohchr.org/Documents/Publications/GuidingPrinciplesBusinessHR_EN.pdf

Irtlach, Kirill. Ian Goodfellow went to work for Apple. ITC.ua. https://itc.ua/blogs/yangudfellou-pereshel-rabotat-v-apple/

James, Tom and Simon Roper. Launching from Earth: The Science Behind Space Law and Technological Developments. In: James T. (eds) Deep Space Commodities. Palgrave Macmillan, Cham. 2018. https://doi.org/10.1007/978-3-319-90303-3 3

Krichevsky, Sergey. Super Global Projects and Environmentally Friendily Technologies Used in Space Exploration: Realities and Prospects of the Space Age. Philosophy and Cosmology, Volume 20, 2018: 92-105. https://doi.org/10.29202/phil-cosm/20/8

Montreal Declaration for the Responsible Development of Artificial Intelligence Launched. https://www.declarationmontreal-iaresponsable.com/la-declaration

Richardson, Rashida, Jason Schultz, and Kate Crawford. Dirty Data, Bad Predictions: How Civil Rights Violations Impact Police Data, Predictive Policing Systems, and Justice. 2019. New York University Law Review Online, Forthcoming. Available at SSRN: https://ssrn.com/abstract=3333423

RoboLaw. Regulating Emerging Technologies in Europe: Robotics Facing Law and Ethics. Official site http://www.robolaw.eu/projectdetails.htm

Scherer, Matthew U. Regulating Artificial Intelligence Systems: Risks, Challenges, Competencies, and Strategies.2015. Harvard Journal of Law \& Technology. http:// dx.doi.org/10.2139/ssrn.260977

Sim, Herbert R. A Force for Space: Artificial Intelligence (AI) Technology? 2018 https:// herbertrsim.com/a-force-for-space-artificial-intelligence-ai-technology/

Skripin, Vladimir. SpaceX otpravila na MKS robota-pomoshchnika CIMON s sistemoy II IBM Watson. ITC.ua. https://itc.ua/news/spacex-otpravila-na-mks-robota-pomoshhnikacimon-s-sistemoy-ii-ibm-watson/

Toronto Declaration: Protecting the Rights to Equality and Non-Discrimination in Machine Learning systems, May 2018, https:/www.accessnow.org/cms/assets/uploads/2018/05/ Toronto-Declaration-D0V2.pdf

van Veen, Christiaan and Cath, Corinne. "Artificial Intelligence: What's Human Rights Got To Do With It?” Data \& Society Points, May 14, 2018, https://points.datasociety.net/ artificial-intelligencewhats-human-rights-got-to-do-with-it-4622ec1566d5

Walker, J.R. The Rise of GEOINT: Technology, Intelligence and Human Rights. In: Ristovska S., Price M. (eds) Visual Imagery and Human Rights Practice. Global Transformations in Media and Communication Research, 2018. https://doi.org/10.1007/978-3-31975987-6_5 